\title{
Importance of seismic wave frequency in FEM-based dynamic stress and displacement calculations of the earth slope
}

https://doi.org/10.2478/sgem-2022-0002

received June 22, 2021; accepted December 16, 2021.

\begin{abstract}
Reliable assessment of earthen dams' stability and tailing storage facilities widely used in the mining industry is challenging, particularly under seismic load conditions. In this paper, we propose to take into account the effect of the dominant frequency of seismic load on the stability assessment of tailing/earthen dams. The calculations are performed by finite element modelling (FEM) with the Mohr-Coulomb failure criteria. To separate the frequency content from other dynamic parameters describing the seismic wave, synthetic waveforms with identical amplitude and attenuation characteristics, but differing spectral characteristics have been used. The analysis has been performed for three different slope angles and two scenarios of seismic wave propagation. Consequently, the changes of total displacement and shear stresses depending on the frequencies have been determined and clearly show that lower frequencies cause higher stress levels and displacement. Finally, the response surface methodology has been applied to determine how different parameters affect the slope stability under dynamic load conditions. Overall, this study is a first step to improve the existing methods to assess slope stability when considering seismic load.
\end{abstract}

\footnotetext{
*Corresponding author: Krzysztof Futawka, KGHM CUPRUM Ltd. Research and Development Centre, 2-8 Sikorskiego Street, 53-659 Wrocław, Poland, E-mail: Krzysztof.fulawka@kghmcuprum.com Anna Kwietniak, AGH University of Science and Technology, Kraków, Faculty of Geology, Geophysics and Environmental Protection, Department of Geophysics, Adama Mickiewicza 30, 30-059 Cracow, Poland

Vera Lay, Technical University Bergakademie Freiberg, Institute of Geophysics and Geoinformatics, Gustav-Zeuner-Str. 12, 09599 Freiberg, Germany; Bundesanstalt für Materialforschung und -prüfung, Unter den Eichen 87, 12203 Berlin, Germany Izabela Jaśkiewicz-Proć, KGHM CUPRUM Ltd. Research and Development Centre, 2-8 Sikorskiego Street, 53-659 Wroctaw, Poland
}

Keywords: Slope stability; Numerical analysis; Seismic load; Frequency analysis.

\section{Introduction}

The world of mining industry produces billions of tonnes of tailings each year. In 2010 only, over 14 billion tonnes of waste material were generated due to mineral processing (Adiansyah, 2015). In most cases, waste material is stored on the surface on so-called tailing storage facilities (TSFs). As it was pointed out by Owen et al. (2020), these facilities are among the world's largest constructions and are characterised by a relatively high failure rate compared to other engineering structures (Duque et al., 2015; Schoenberg, 2016; Gobla, 2017). As observed in recent years, the failures caused by loss of slope stability are becoming more and more frequent. According to the International Commission on Large Dams (ICOLD, 2020), since the beginning of the 21st century, the disaster related to earthen dams' slope stability has occurred statistically at least once a year. A detailed analysis of TSF failure rate was presented by Azam and Li (2010). According to the data, until the end of 1950, the number of failures was no greater than 10 per decade. The beginning of 1960 brought a sudden rise in this number that lasted till 1980 (up to 50 per decade). This growth is associated with vivid mining activity after World War II (WWII). The growing demand for iron ore led to increased excavation that resulted in a higher failure rate. Chambers and Higman (2011) suggest that the rise in failure rate might also be related to the enlarged size of used vehicles and machinery. After that, at the beginning of the 1990s, with advances in technology, the failure rate started to decrease (compared to the previous decade, there was a $60 \%$ drop in failure rate). The success is also attributed to the regulations introduced for evaluating the stability of the constructions. Nevertheless, despite rapid developments of new technologies and monitoring performed at the sites, the annual number of 
dam failures started to increase again after 2000. Thus, the TSF failures are still a threat to safety in the mining industry, which mainly depends on man-made decisions. These critical mistakes might happen at the planning step, during exploitation and even after the closure of the post-exploitation ponds. It should be highlighted that due to the technical requirements, storage facilities might exist in different environments that are statistically nonuniform and are exposed to many risk factors (Pytel, 2010). Therefore, each case should be analysed and monitored separately, fitted to the specific surrounding conditions.

Based on case studies (Rico et al., 2008; Azam \& Li, 2010; Glotov et al., 2018, Turi et al., 2013, Roche et al., 2017), one may conclude that the main reasons for earthen dam failures at the end of 21st century were:

- wrong location;

- insufficient geological, hydrogeological and meteorological (mainly rainfall rate) recognition of the site;

- improper management and lack of maintenance during exploitation;

- faulty paradigms of the physical models used for stability assessment during dam's lifespan and

- underestimation of the dynamic parameters basing on statical and pseudo-static parameters for physical models.

As pointed out by Vogel (2013), due to numerous TSF failures worldwide, there were almost 2400 fatalities between 1961 and 2020 (Owen, 2020; WISE, 2019), and we may expect that in the next few years, along with the increase of tailing production, this number will further increase (NRGI, 2017, Owen, 2020). There are numerous possible reasons for such a situation like the continuous expansion of dam volume due to the facility development, an increase of tailings and seepage volume (Dhungana, 2020) or intensification of extreme rainfall occurrence due to climate change (Myhre et al., 2019). On the other hand, in some cases, the exact reasons are unknown, which could lead to the conclusion that some mistakes have been made during the facility project and development or risk evaluation. Therefore, there is a vital necessity to develop new geotechnical slope stability assessment methods and to implement a more accurate risk monitoring system. This topic gains importance, especially in the mining industry, where tailings of high volume are produced every year. Moreover, TSF located near areas of mining activity are often affected by additional factors like paraseismic activity, mininginduced seismicity, rock bursts or ground settlement, which make the issue of slope stability evaluation even more complicated (Fulawka et al., 2019, 2020; Domańska \& Wichur, 2006; Suddle, 2009; Aven, 2010).

\subsection{TSF failures - what we learnt so far}

As pointed out by Adamo et al. (2020), earthquakes may cause significant damages or even dam failures. According to historical cases, additional seismic load affects mainly earthfill dams or TSFs. The meaningful reports about the failure statistic were presented by the United State Committee on Large Dams (USCOLD, 2000) and the United States Society on Dams (2014), where numerous cases of visible dam damages and failures observed between 1896 and 2013 had been analysed concerning the seismic source energy and location. According to these reports, previous dam analyses were performed with respect to the maximum acceleration recorded or predicted at the base and on the crests of the dams. Still, when analysing past failures, one may conclude that in many cases, the quakes with higher energy and lower epicentral distances from the slope may generate lower damages in the construction than more distant, weaker events. Such a situation may lead to the conclusion that the energy of earthquakes, related to their amplitudes, is not the only factor affecting the overall slope stability. Other parameters of the seismic load, such as frequency content, need to be taken into account to determine their influence on slope stability. The direct impact of the earthquake may be related to the seismic load frequency and the natural frequency of the particular dam.

This hypothesis may be supported by recently observed catastrophic tailing dam failures in Brazil. In the last years, two significant disasters occurred: in the state of Minas Gerais, which is known for ore exploration, on 5 November 2015 (Samarco Mine) and in Córrego do Feijão iron ore mine in Brumadinho on 25 January 2019 (estimated causalities 270). Both mines are owned or partly owned by VALE Corporation. The first one, the Mariana dam disaster (also found under 'Bento Rodriguez' or 'Samarco' dam disaster), was described in detail by Agurto-Detzel et al. (2016). The authors propose the occurrence of seismic events as being the triggering factor of the dam disaster. The Brazilian Seismographic Network registered eight events spread out over 4 days. The local magnitudes $\left(\mathrm{M}_{\mathrm{L}}\right)$ were estimated between 1.3 and 2.6, and the moment magnitudes $\left(\mathrm{M}_{\mathrm{w}}\right)$ ranged 0.7-2.0. The analysis suggested shallow events, up to a depth of $5 \mathrm{~km}$, which is sustained by the fact that the events were felt by the mine staff (intensities at the level of IV-V in modified Mercalli intensity scale). The event seismograms' high cross-correlation suggested that these earthquakes should have had similar focal mechanism and location.

It should be noted that all events could not be detected automatically (the closest station was at the distance of $160 \mathrm{~km}$ from the seismic source) and their 
analysis was only possible manually. This fact suggests the need to deploy broadband seismometers at the mining sites, which could be sensitive for a wide range of signals, even those of smaller magnitudes. Because of the lack of a sensitive monitoring system at the dam slopes, the exact evaluation of amplitude and frequency characteristics in the conducted risk evaluations and stability assessment was impossible. Nevertheless, according to the regional seismic monitoring system, seismic events occurred in the site's vicinity. Such sources can be understood as diffusive seismic sources, and the area of Minas Gerais is a region of low seismicity (Agurto-Detzel et al., 2016). In the region, only one seismic event of magnitude 5.1 occurred (Castañeda et al., 2013). Minas Gerais state is a mining region (hence the name) and might also be a subject of mining-induced seismicity, mainly related to blasting; however, the described events have a natural character. The Mariana case proves that even low-energy seismic sources can severely threaten a tailing dam, especially when the epicentre distance is small. Such cases are rare, but the resulting damage might be compared to similar failures caused by stronger magnitude earthquakes, for instance, events from Chile in $1928(\mathrm{Mw}=8.2)$ and 1965 $(\mathrm{Mw}=7.5)$ (Adamczyk, 2012). The second meaningful and the most recent and catastrophic example of tailing dam failure is the event from Brumadinho in 2019. In Córrego do Feijão iron ore mine, the stability of the tailings dam was evaluated using pseudo-static limit equilibrium method (LEM) that takes into account acceleration (Jibson, 2011) and is independent of ground shaking frequency. The estimated factor of safety (FoS) of slope stability was determined to be 1.5, which theoretically should ensure sufficient safety margin even under the seismic load condition. Still, this evaluation did not include the frequency value, which seems to play a critical role in evaluating dam stability (Santamarina et al., 2019).

Slope stability estimation needs more detailed analysis, especially in regions commonly not considered as potentially hazardous, but still exhibit low seismicity rate $(\mathrm{Mw}=2-3)$. For instance, in Poland, many geotechnical waste sites are built in areas where moderate seismicity occurs, both natural (Guterch, 2009) and induced (Mirek \& Mirek, 2011). For these regions, there is currently no routinely performed analysis regarding the frequency of a seismic wave (Adamczyk et al., 2013).

In this paper, we show that the dominant frequency of events should not be neglected in analyses and the magnitude is not the only factor that should be considered during slope stability evaluation. We will concentrate on the parameters of a seismic signal (seismic load) and, for now, will not focus on the exact source of the shaking, since its origin (natural or induced) plays a secondary role in the presented analysis.

\subsection{Dominant frequency in civil engineering}

In general, the term seismic load may be defined as any ground movement caused not only by, for example, natural or induced seismicity, but also seismic noise produced by traffic, machinery or active seismic surveys. This ground motion may be described by factors such as amplitude, frequency of vibration and duration. When considering the frequency content of seismic load, the analyses conducted in other civil engineering branches may be a good reference point. For example, according to the International Atomic Energy Agency (IAEA, 2004), when analysing the influence of seismic load on the nuclear object, an adequate input ground motion should be determined. This input should consist of parameters such as earthquake intensity, energy, epicentral distance, maximum acceleration, duration and frequency characteristics. In the safety standards, it is recommended to study the S-wave velocity to a depth of $30 \mathrm{~m}$ (Vs30), since it predominates the amplification factor (IAEA, 2004). Considering shear stress, Vs30 is one of the parameters for which the non-linear site amplification effect occurs (Walling et al., 2008). The site amplification effect, influencing the acceleration spectra's amplitude, is higher for lower velocity values. This effect is crucial, especially in non-active areas for which the peak ground acceleration does not exceed $0.1 \mathrm{~g}$ (where $g$ is the mean value of gravity at the Earth's surface with an acceleration of about $9.8 \mathrm{~m} / \mathrm{s}^{2}$ ). Moreover, surface waves of seismic events, which are almost entirely responsible for eventual damage, have lower frequencies than body waves (P- and S-waves). Hence, for slope stability assessment, not only the maximal amplitudes related to a specific type of wave, but also the frequency content of seismic waves should be taken into account.

The same conclusion may be drawn when reviewing the Polish Mining Intensity Scale (2018) that matches the maximal observed energy of a seismic event to a frequency, which is the first step to evaluate an event's intensity. The scale is non-linear, which results in a possibility that same energy events will be classified into different intensities (Fulawka et al., 2019, 2020). Similarly, Eurocode 8 regulations (2004) consider the frequency characteristic for assessing a wide range of parameters that describe viscous damping, system vibration and response functions. Nevertheless, in the case of geotechnical facilities, essential parameters such as frequency are almost entirely neglected. 
This paper aims to highlight the dynamic parameters' role and the frequency content for stability evaluation of tailing/earthen dams. For this, analytical solution and numerical modelling will be presented using finite element-based numerical analysis subjected to dynamic load in the form of damped harmonic vibration characterised by different frequency content.

\section{Recently used methods of slope stability assessment}

The methods currently used to assess slope stability required by national regulations, laws and standards are generally based on the analytical methods from the past decades. The first documented research in the field of slope stability was presented in the late 18th century (Coulomb, 1777). Significant improvement of calculation accuracy may be dated to late 20th century when the method of slices was developed and presented by Petterson (1955). This method assumed a circular failure interface and was later improved by Fellenius (1927) and Terzaghi (1925). As a result, fundamental methods of slope stability calculation were designed and have been used ever since. After the WWII, a rapid development of stability assessment methods was observed. The sudden growth in the mining industry resulted in dozens of tailings pond disasters; consequently, vital necessity for accurate risk assessment methods arose. As a result, Janbu (1954) proposed a new assessment method based on slices that only considered total horizontal force equilibrium instead of total moment equilibrium. After that, Bishop (1955) proposed new methods for which the resultant interslice forces were horizontal. At the same time, there were no vertical interslice shear forces. In the $60 \mathrm{~s}$ of the 20th century, iterative methods were introduced to geotechnical software, which was a milestone in slope stability calculations. Parallel to that, more reliable approaches were proposed by Morgenstern and Price (1965) and Spencer (1967). The first one (Morgenstern \& Price, 1965) assumes that the resultant interslice forces' direction is defined using an arbitrary function. The fraction of the function's value needed for force and moment balance is computed. In the second one (Spencer, 1967), the resultant interslice forces have a constant slope throughout the sliding mass. All the methods described above are used in LEM analyses, which are most commonly used in slope stability assessment and allow to calculate FoS of slope under additional load occurrence, that is, vibration caused by mining tremors (Melo \& Sharma, 2004; Choudhury et al., 2007; Hazari et al., 2020). The additional seismic load is implemented into the calculation with so-called seismic force $F S$ according to the formula given below:

$$
F_{S}=\frac{a \cdot W}{g}=k \cdot W
$$

where $a$ is the maximum amplitude of recording seismic wave acceleration $\left(\mathrm{m} / \mathrm{s}^{2}\right), W$ is the weight of the slice $(\mathrm{kN})$, $g$ is the acceleration of gravity, $g=9.81\left(\mathrm{~m} / \mathrm{s}^{2}\right)$ and $k$ is the acceleration ratio $(a / g)$.

As pointed out by Liu et al. (2015), LEM calculations are very efficient in terms of time consumption, but also have some limitations, that is, the slip surface location must be predefined. In complex geological conditions, finite element (FE)-based methods have been proven to be more useful and reliable (Cheng et al., 2007; Griffiths \& Lane, 1999; Zheng et al., 2005).

The shear strength reduction (SSR) method was proposed by Zienkiewicz et al. (1975) to determine soil slope stability with the use of FE. In this method, the safety factor (SF) is defined as the ratio of observed shear strength to the minimum shear strength required to prevent loss of stability (Duncan, 1996). As pointed out in numerous researches (Shangyi et al., 2003; Yingren \& Shangyi, 2004; Hammah et al., 2007), the SSR method was applied for soil slopes and rock masses as well due to its high reliability and universality. Yingren and Shangyi (2004) demonstrated the efficiency of the SSR method for slopes of soil and rock masses. The main advantage of the SSR method over LEM is that the analysis does not require any assumptions of the interslice shear force distribution and the critical failure surface location. According to Chiwaye (2010), visible differences in estimated volumes of failure in LEM and SSR methods may be observed. In general, the SSR method gives more significant volumes of failure.

In general, the SSR method examines the value of the stress reduction factor (SRF), which leads to slope failure. The shear strength reduced by an SF can be found using a series of iterations to fit the friction angle $\left(\varphi^{\prime}\right)$ and the cohesion ( $c^{\prime}$ ) of the slope. When using the Mohr-Coulomb criterion, the process of SSR may be expressed according to the following equations:

$$
\begin{gathered}
\tau=c^{\prime}+\sigma^{\prime} \tan \varphi^{\prime} \\
\frac{\tau}{\mathrm{SF}}=\frac{c^{\prime}}{\mathrm{SF}}+\frac{\sigma^{\prime} \tan \varphi^{\prime}}{\mathrm{SF}}
\end{gathered}
$$

where $c^{\prime}=\frac{c^{\prime}}{S F}$ is the reduced value of cohesion and $\varphi^{\prime}=\arctan \left(\frac{\mathrm{S}\left(\frac{\mathrm{S}}{\mathrm{SF}} \varphi^{\prime}\right.}{\mathrm{SF}}\right)$ is the reduced value of internal friction angle. 


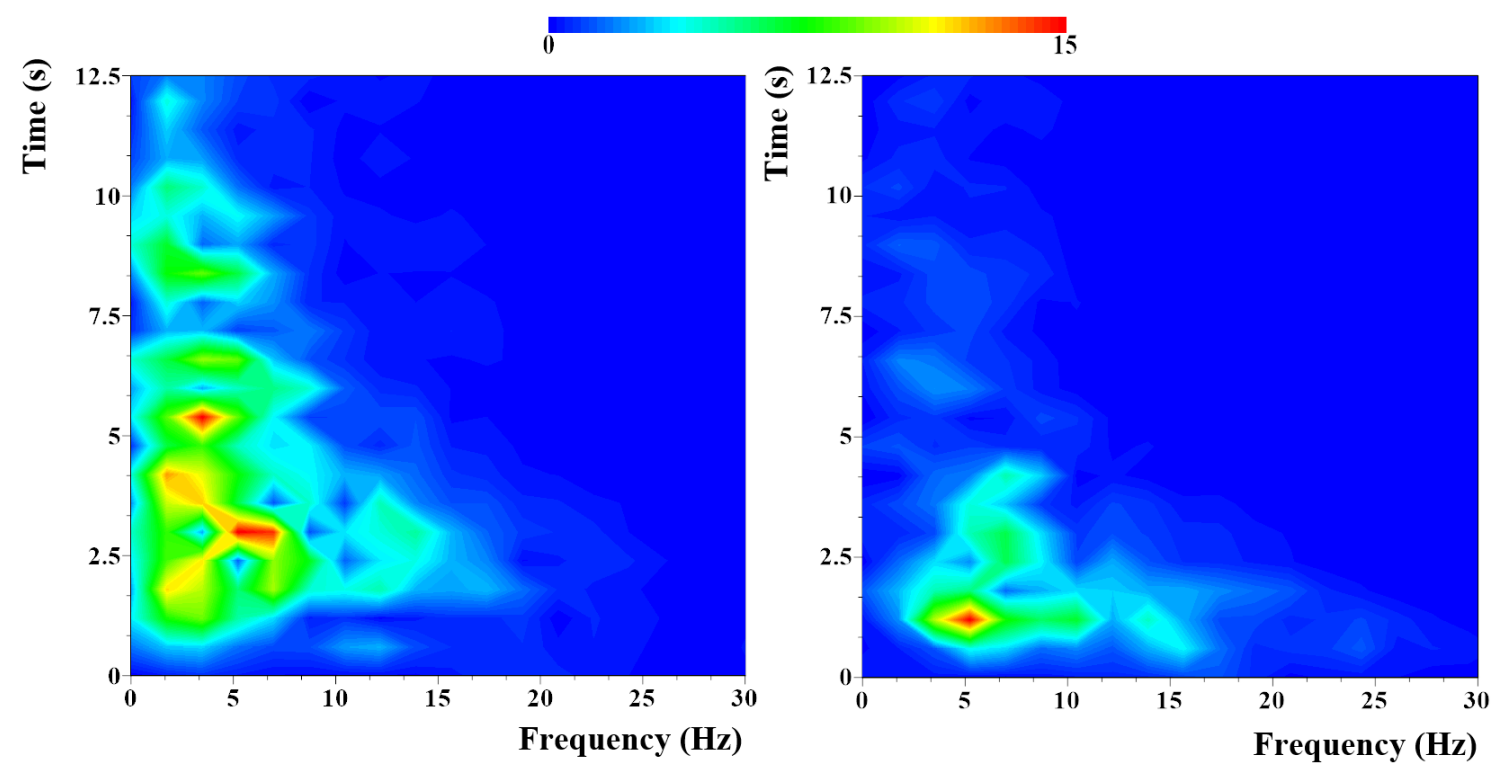

Figure 1: Comparison of spectrograms for mining-induced high-energy tremors with energy of $1.9 \times 10^{9} \mathrm{~J}$ (left) and $1.2 \times 10^{7} \mathrm{~J}$ (right).

Despite showing good reliability and some advancements compared to LEM calculations, the SSR technique is still conducted in the so-called pseudo-static conditions, where the seismic load is defined in the model as a permanent body force representing one peak value of ground shaking.

As it may be noticed, the pseudo-static approach utilised in both LEM- and finite element method (FEM)based analyses does not allow to include dominant frequency content of seismic wave into the calculation. As a result, this method seems to be fully reliable only in static slope stability analysis or may provide a preliminary evaluation of the geotechnical structure's stability. Nevertheless, in many countries, for example, according to Polish regulations, SF, which can be determined only with static or pseudo-static methods, is an obligatory parameter that needs to be determined before obtaining permission for flotation tailing pond construction. However, nonstatic characteristics play a significant role. According to equation (4), displacement is inversely proportional to frequency. Consequently, when the frequency decreases, displacement rises:

$$
D=\frac{v}{\pi \cdot F}=\frac{g \cdot a}{2 \pi^{2} F^{2}}
$$

where $v$ is the amplitude of seismic wave velocity $(\mathrm{m} / \mathrm{s})$, $F$ is the frequency $(\mathrm{Hz}), a$ is the maximum amplitude of recording seismic wave acceleration $\left(\mathrm{m} / \mathrm{s}^{2}\right)$ and $g$ is the acceleration of gravity, $g=9.81\left(\mathrm{~m} / \mathrm{s}^{2}\right)$.
The Short-Time Fourier Transform (STFT) analysis shows that the relative energy distribution of a seismic wave depends on the amplitude and the dominant frequency content of this seismic wave. In Figure 1, two waveforms recorded after high-energy mining-induced tremors in Legnica-Głogów Copper Basin (LGCB), Poland, are presented. Both tremors are characterised by the same level of maximum vibration amplitude, which determines the same result of calculation in pseudo-static analyses. Nevertheless, it should be highlighted that both events differ with the frequency content. The first one was the mining event with an energy of $1.9 \times 10^{9} \mathrm{~J}$ and a hypocentral distance from the seismic recording station of $6385 \mathrm{~m}$. The second one was a tremor with an energy of $1.2 \times 10^{7} \mathrm{~J}$ and a hypocentral distance from the seismic post of $2683 \mathrm{~m}$ (Figure 1).

Figure 1 shows the different characteristics of recorded seismic events in terms of the energy dissipated at specific frequencies. As it can be seen on the spectrograms, both tremors create different characteristics of relative seismic energy distribution. Tremor with lower energy located in near field generated only one significant amplitude peak with the dominant frequency of $5 \mathrm{~Hz}$. In turn, high-energy tremor with two times longer hypocentral distance from the seismic post generated substantial energy peaks in the frequency range of 2-7 Hz. Moreover, this energy took longer to dissipate, which potentially might affect the nearby facilities more destructively.

The reliable effect of seismic wave frequency content on geotechnical facilities' stability can be analysed using 


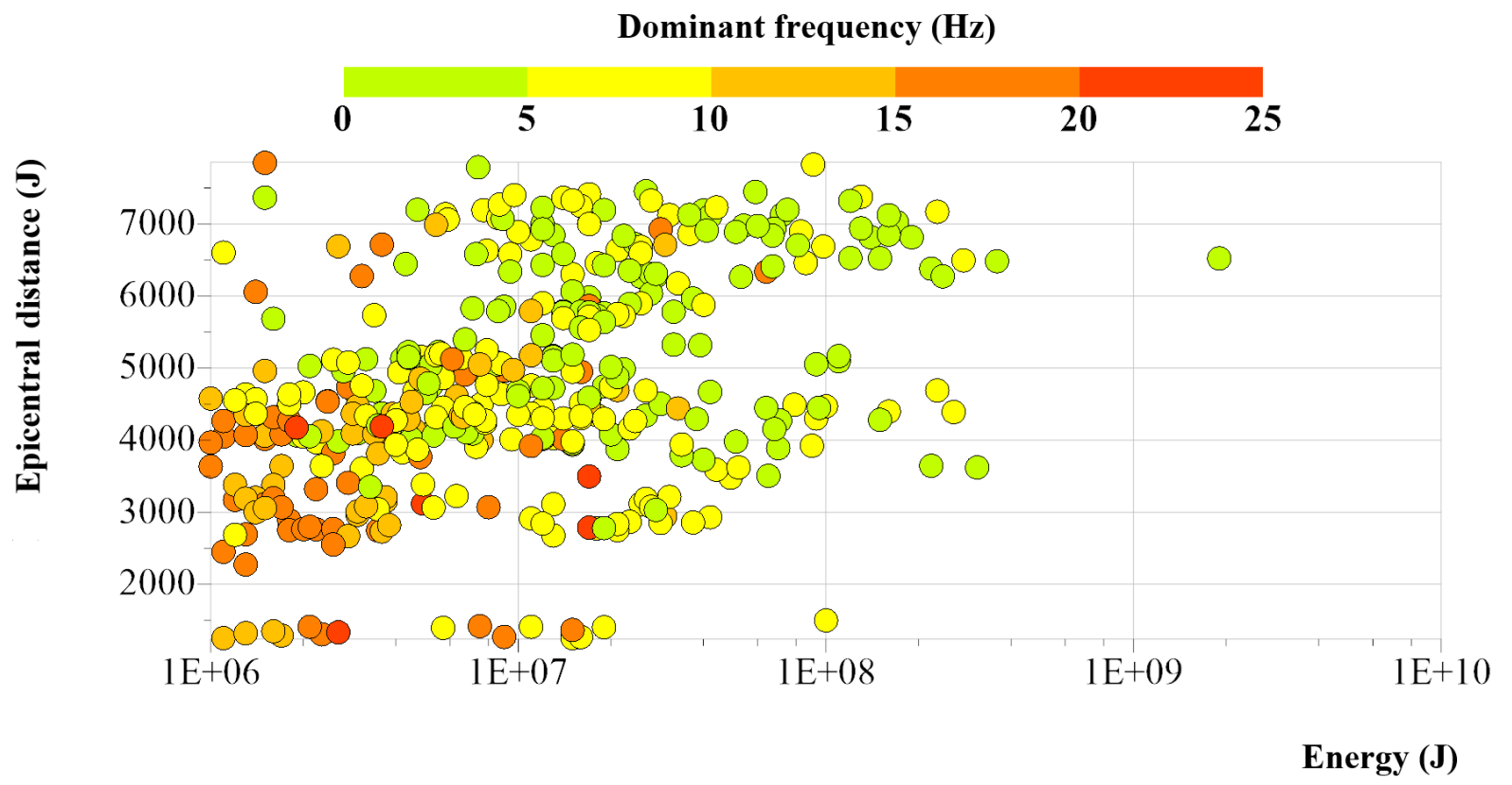

Figure 2: The dominant frequency content of LGCB mining-induced tremors in relation to their epicentral distance and energy (over 430 entries, vertical and horizontal components were studied).

FEM analysis under dynamic conditions (Kucewicz et al., 2020; Baranowski et al., 2020). These methods allow determining how the frequency rate and the duration of dynamic load affect slope stability. Thus, considering the frequency content of the analysed seismic wave is of great importance when assessing the slope stability.

\section{The spectral characteristics of the waveforms recorded in LGCB}

For this analysis, 2D FEM-based numerical models are prepared. As seen for the real seismic events (Figure 1), the seismic wavefield contains a wide frequency range. In order to simulate this effect, the synthetic waveforms that are applied here have different dominant frequencies. As it was concluded by Pytel et al. (2019), for the events in LGCB, the observed dominant frequencies of high-energy mining-induced events depend on their hypocentral distance. The frequency band from these events ranges between 0.8 and $24 \mathrm{~Hz}$ (Figure 2).

As one may conclude, the distribution of dominant frequency varies significantly with the changes in tremors' energy and their spatial distribution. Still, there is a general trend of frequency decreasing with increase of epicentral distance and energy of the seismic event. As a result, moderate energy tremors located in close epicentral distance from the measuring site are characterised by dominant frequencies in the range of 10 $\mathrm{Hz}$ up to $25 \mathrm{~Hz}$. In turn, seismic waves induced by highenergy tremors, which occur at a distance of $5 \mathrm{~km}$ or larger from the measuring point, are characterised by relatively low frequencies, which in most cases do not exceed $5 \mathrm{~Hz}$.

\section{Materials and methods}

\subsection{Simulation of artificial waveforms with different dominant frequencies}

To determine precisely how and if the seismic wave's dominant frequency affects the stresses and displacement within the slope, synthetic waveforms with the same amplitude and damping coefficient, but different bandwidth were prepared. Waveforms are determined according to the formula given below:

$$
a_{(t)}=a_{\max } \cdot \exp (-\beta \cdot t) \cdot \cos ((\omega \cdot t)+\varphi)
$$

where $a_{(t)}$ is the amplitude of seismic wave acceleration in each time step $\left(\mathrm{m} / \mathrm{s}^{2}\right), a_{\max }$ is the maximum amplitude of seismic wave acceleration before attenuation $\left(\mathrm{m} / \mathrm{s}^{2}\right), \beta$ is the attenuation factor $(1 / \mathrm{s})$, $t$ is time $(\mathrm{s}), \mathrm{w}$ is the natural frequency (rad/s) and $\varphi$ is the initial phase (rad).

As a result, 30 synthetic waveforms with an amplitude of $800 \mathrm{~mm} / \mathrm{s}^{2}$ and a duration of $4 \mathrm{~s}$ were prepared. The 


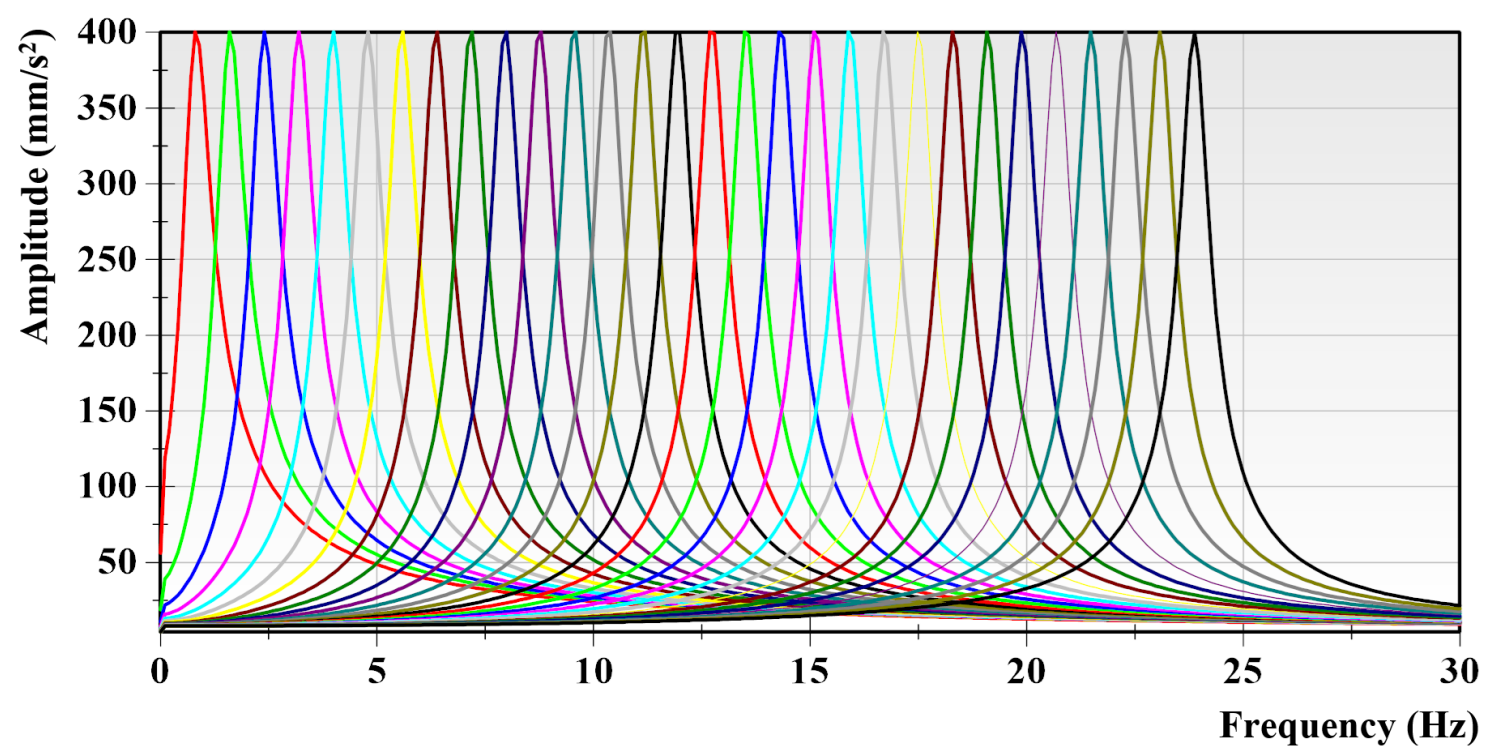

Figure 3: The spectral amplitude characteristic of harmonic signals used in FEM dynamic analysis.

result of the fast Fourier transform for each waveform is presented in Figure 3.

It may be noticed that the spectral distribution of simulated synthetic records is characterised by clearly visible, single dominant frequency of vibrations. Such an approach ensures separation of the influence of frequency on stress and displacement distribution in slope from other parameters describing seismic waves, such as time, amplitude and attenuation.

\subsection{Preparation of 2D FEM model}

All numerical calculations were conducted in RS2 software for 2D FE soil and rock geotechnical analyses. The dynamic analysis utilised in RS2 software is generally based on the Newmark time-stepping methods. In turn, as a failure criterion, the Mohr-Coulomb criteria have been used, which is one of the most commonly utilised solutions in geotechnical analyses (Zhao, 200; Owen \& Hinton, 1980; Pietruszczak, 2010; Labuz \& Zang, 2012). It is based on the assumption that there exists a linear relationship between shear strength $\tau$ on a plane and the normal stress $\sigma_{n} \sigma_{n}$ acting on it. The following formula describes this relation:

$$
\tau=c-\sigma_{n} \tan \varphi
$$

where $c$ is the cohesion $(\mathrm{kPa})$ and $\varphi$ is the angle of internal friction $\left({ }^{\circ}\right)$.

Boundary conditions were specified as an absorbing (bottom) and a transmitting (left and right) boundary, which prevents generating dynamic reflections within the model. The details about both boundary conditions are described in RocScience (2021). The initial assumptions in terms of material properties and slope geometry are presented in Figure 4. Three different slope angles, that is, $20^{\circ}, 34^{\circ}$ and $45^{\circ}$ are modelled separately.

The strength parameters of soil used during the model preparation have been presented in table 1 .

For this analysis, the material type of the slope was defined as plastic. The critical factor affecting the reliability of dynamic FE analysis is the mesh size. Too long boundaries of elements can negatively affect the ability of the model for high-frequency transmission. Numerical falsification of the propagating wave characteristic of a dynamic analysis may result from incorrect modelling conditions. In the case of additional seismic load in FE analysis, both frequency content and velocity affect the numerical accuracy of wave transmission through the model. According to Kuhlemeyer and Lysmer (1973), the exact interpretation of wave transmission across a numerical model requires that the spatial size element $\Delta \mathrm{l}$ must be smaller than $10 \%$ of the wavelength coupled with the highest frequency.

$$
\Delta l=\frac{\lambda}{10}
$$

where $\lambda$ is the wavelength associated with the highest frequency of seismic wave (m).

Examples of this type of problem include seismic analysis of surface structures such as dams or dynamic analysis of underground excavations. Therefore, the 
- Unit weight: $19\left[\frac{\mathrm{kN}}{\mathrm{m}^{3}}\right]$;

- Young modulus: $100000[\mathrm{kPa}]$;

- Poisson ratio: 0.4 [-];

- Tensile strength: $5[\mathrm{kPa}]$;

- Cohesion: $5[\mathrm{kPa}]$;

- Friction angle $38^{\circ}$

- Material type: Plastic,

- Dilation angle: $0^{\circ}$

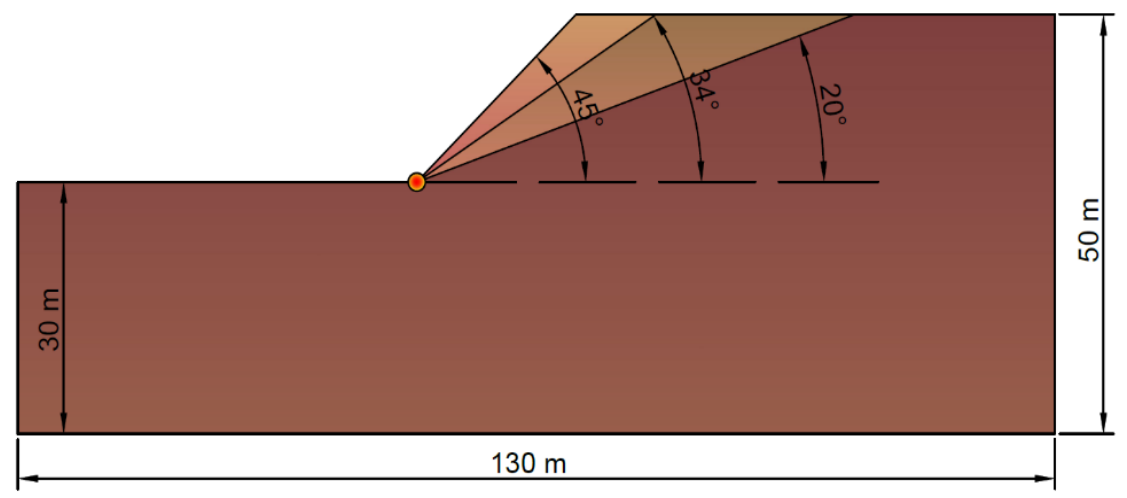

Figure 4: Geometry of slope used for numerical simulation.

Table 1: Material parameters used for numerical simulation.

\begin{tabular}{llllllll}
\hline Parameter & Unit weight & Young modulus & Poisson ratio & Tensile strength & Cohesion & Friction angle & Dilation angle \\
\hline Unit & $\mathrm{kN} / \mathrm{m}^{3}$ & $\mathrm{kPa}$ & - & $\mathrm{kPa}$ & $\mathrm{kPa}$ & $\circ$ & 0 \\
Value & 19 & 100,000 & 0.4 & 5 & 5 & 38 & 0 \\
\hline
\end{tabular}

maximum mesh element size with respect to the capability of the model to transmit particular frequency content, $f$, may be calculated according to the following formula:

$$
\Delta l=\frac{C_{s}}{f \times 10}
$$

where the shear wave velocity $C_{s}$ can be calculated using the following equation:

$$
C_{s}=\sqrt{\frac{E}{2(1+v)\left(\frac{\rho}{g}\right)}}
$$

The maximum calculated size of a single FE element is presented in Figure 5.

According to the calculations for the lowest frequencies, where the wavelength is relatively high, the spatial element size should not be larger than $17 \mathrm{~m}$. In turn, with an increase of frequency, smaller size of elements is required. In the case of $24 \mathrm{~Hz}$, all elements in the mesh should not exceed $0.57 \mathrm{~m}$. One may notice that Kuhlemeyer and Lysmer law is valid for low-frequency excitations rather than for high-frequency excitations, because for small frequencies, the obtained results are too large to obtain model convergence. Thus, to ensure the stability of calculation, the single element size in analysed models has been a few times smaller than that resulting from Kuhlemeyer and Lysmer law.

\section{Effect of dominant frequencies on the slope under dynamic load}

Two options were considered to investigate how the seismic load direction affects the slope's stress/strain condition. In the first case, the direction of seismic wave propagation was opposite to the direction of slope failure, which is often observed in slopes located on areas of mining-induced seismicity. In the second scenario, the direction of seismic wave propagation was the same as the slip surface. In this case, the expected load and the slip forces acted in the same direction (Figure 6). The seismic load was applied near the intersection of the bottom and vertical boundaries (yellow points). The point of the model subjected to analysis was located at the bottom of the slope (blue point).

Combining all parameters such as three slope angles, two seismic wave propagation directions and 30 dominant frequencies, a total of 180 different numerical models were calculated (Figure 7). To investigate how the frequency content of dynamic load affects the slope, changes in stress and displacement values at the bottom of the slope were analysed.

The example of stress and displacement changes over time in the dam with a $45^{\circ}$ slope angle are presented in Figure 8. The Y-axis represents logarithmic changes in stress and displacement. The calculations summarised in Figure 8 clearly show that variations in the dominant 


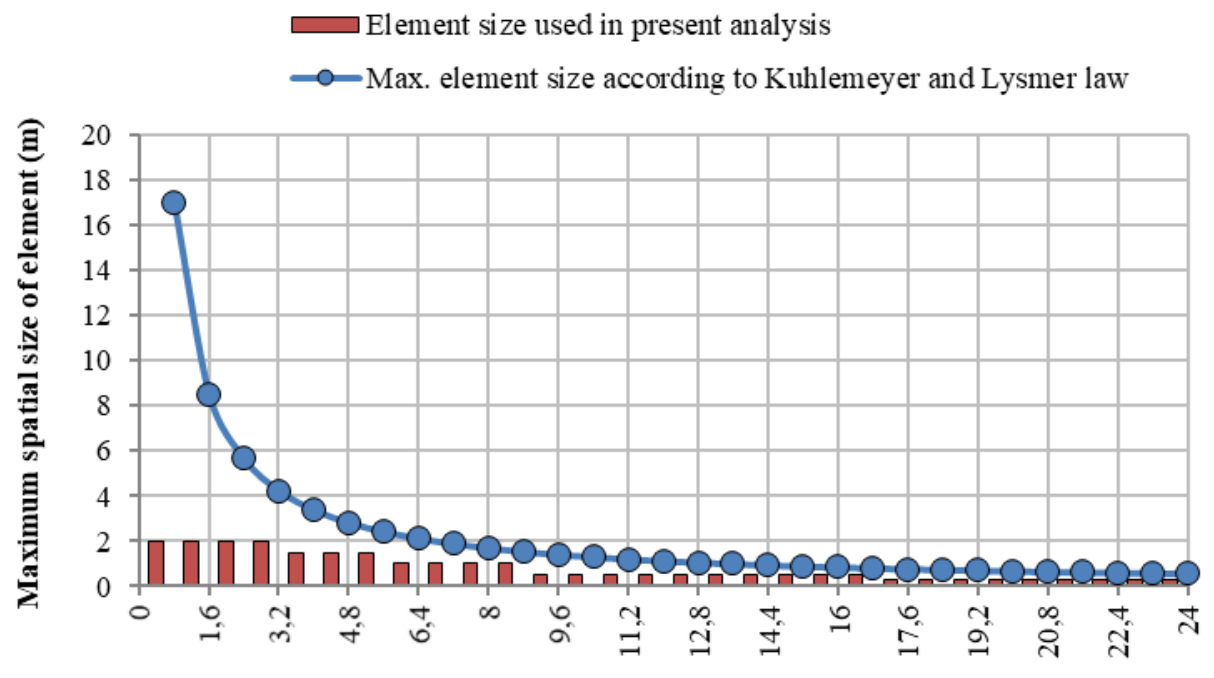

Maximum frequency of seismic wave $(\mathrm{Hz})$

Figure 5: Maximum element size in the dynamic model according to Kuhlemeyer and Lysmer law (blue line) and element size used for the purposes of this analysis (red bars).

Point of seismic load assignment

Point subjected to analysis of stress/deformation changes

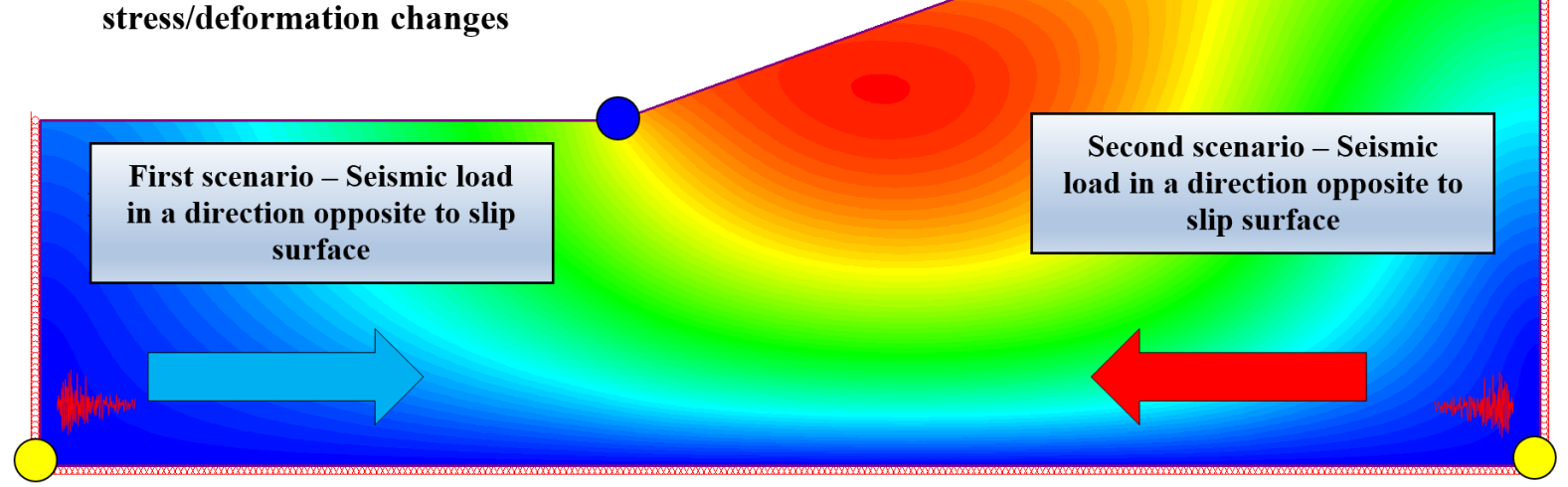

Figure 6: Analysed variants of seismic load direction.

frequency of the seismic wave may generate a significant difference in the overall state of the slope stress and displacement distribution. One may observe that the difference between 0.8 and $24.0 \mathrm{~Hz}$ reaches over $99 \%$ in the total displacement values and $94 \%$ when analysing the obtained shear stress.

For low frequencies (particularly $0.8 \mathrm{~Hz}$ ), the maximum displacement is as large as $60 \mathrm{~mm}$. In the case of 0.8 and $1.6 \mathrm{~Hz}$ harmonic motions, the most significant differences are visible at the base of the slope for both shear stresses and displacements. Such a situation may be caused by interference with the natural frequency of the analysed slope. For frequencies exceeding $8.0 \mathrm{~Hz}$, no significant displacement is visible.

Similar conclusions may be drawn when examining the maximum value of the total displacement and shear stress at the slope's base in all analysed scenarios. The distribution of total displacement and shear stress over different dominant frequency content is presented in Figure 9 (vertical scale is logarithmic). According to the obtained results, the slope's angle affected shear stresses and displacements at the bottom of the slope less significantly than the dominant frequency of the seismic wave. With the increase of frequency, the exponential 


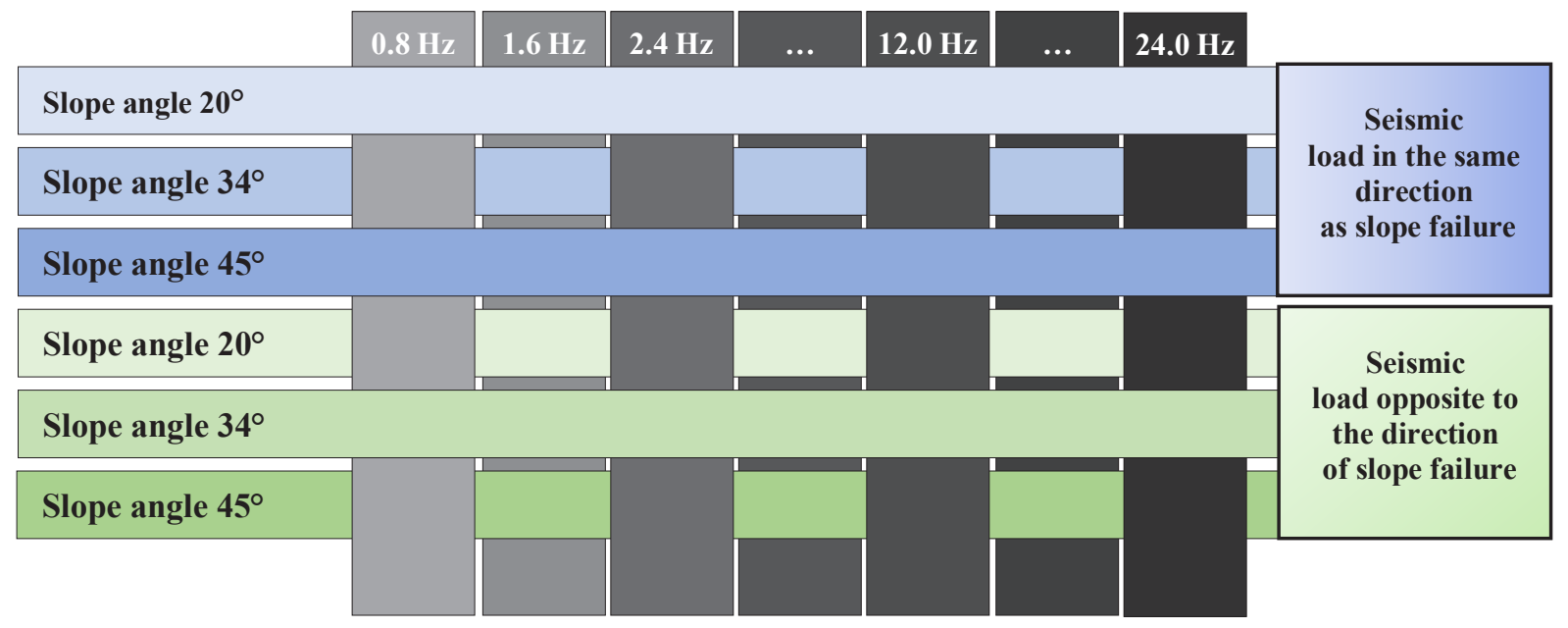

Figure 7: Matrix of numerical scenarios used for the presented research.
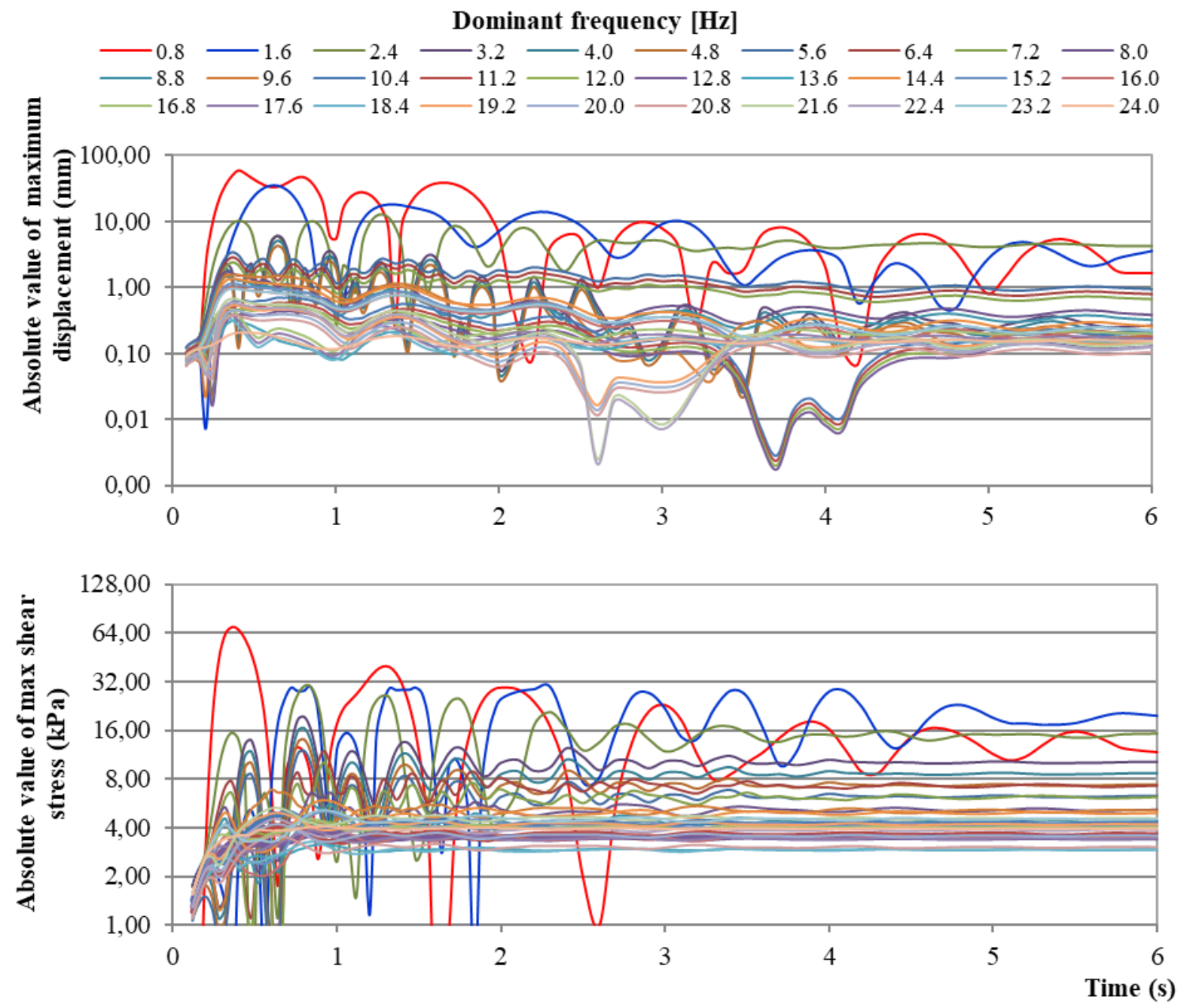

Figure 8: The calculated absolute values of displacement (top) and shear stress (down) changes at the base of the analysed slope depending on the used frequency. 

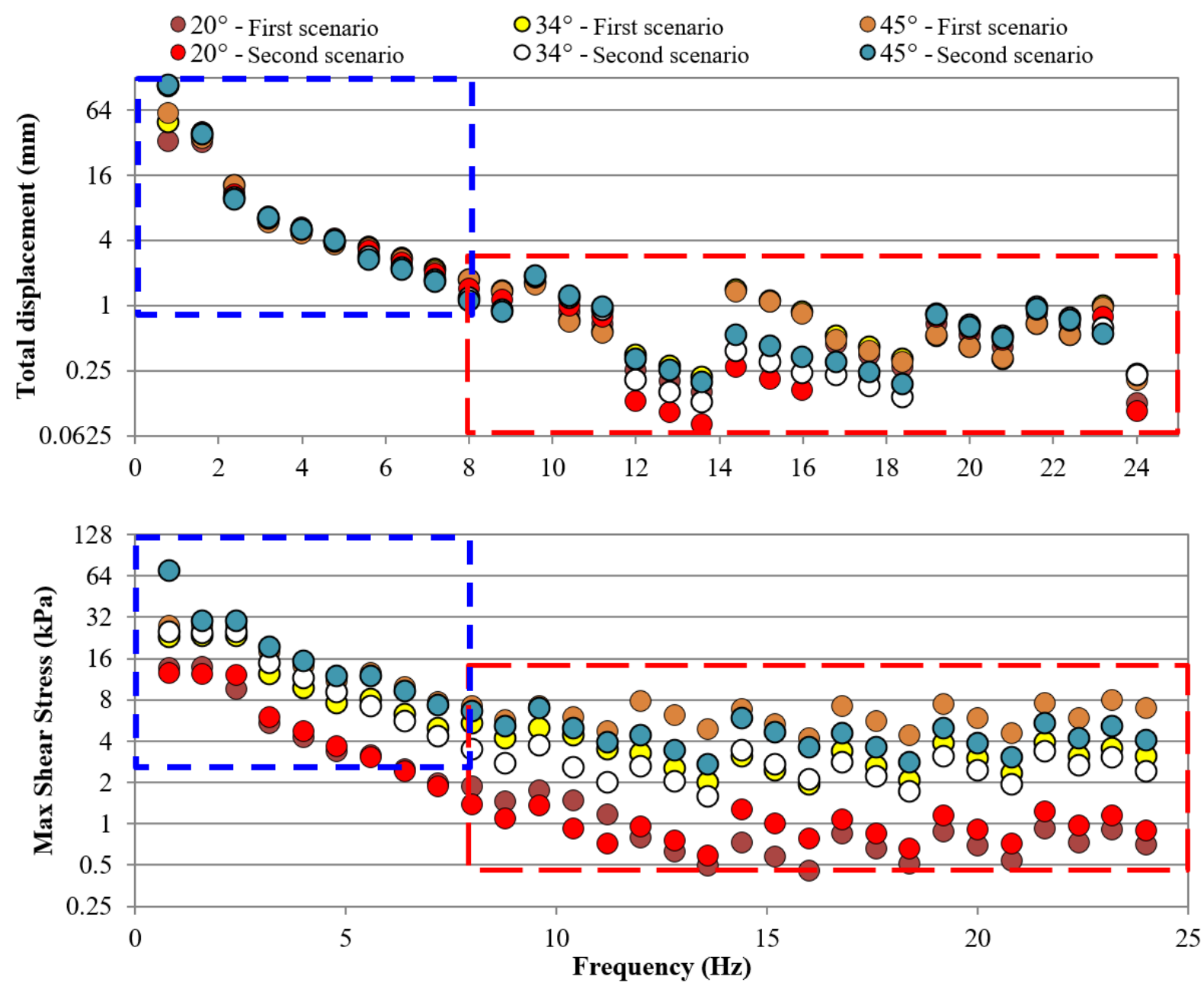

Figure 9: The maximum calculated value of total displacement (top) and shear stress (bottom) at the base of the slope for all 180 cases.

drop observed in displacement should be highlighted. Concerning the slope angle, visible differences in the result may be observed only for a frequency of $0.8 \mathrm{~Hz}$. When analysing the maximum calculated dynamic displacement at the base of the slope, it may be observed that the most significant movements of $107 \mathrm{~mm}$ were calculated in the case of the slope angle of $45^{\circ}$ with the seismic load direction consistent with the direction of slope failure. In turn, the lowest dynamic displacement $(32 \mathrm{~mm})$ was observed in the case of the slope angle of $20^{\circ}$ with seismic load propagating in the direction opposite to that of slope failure. Unexpectedly, it was found that there was a clear lower limit value of dominant frequency $f=8.0 \mathrm{~Hz}$ that determined visible changes in the observed displacement. When analysing the displacement changes in the frequency range between 0.8 and $8 \mathrm{~Hz}$ (blue box), a clear exponential downward correlation may be observed. In comparison, for frequencies higher than $8.0 \mathrm{~Hz}$, the total displacement at the base of the slope does not exceed
$2 \mathrm{~mm}$ in all 180 analysed cases. In this area (marked with the red box), the clear trend line is hard to find due to the significant variation of results. The foremost cause of such discrepancy is a time-step limitation of the software. Nonetheless, the scatter of the results, below $1 \mathrm{~mm}$, is the uncertainty that is acceptable from a geotechnical point of view.

A comparable conclusion may be drawn when analysing the total calculated shear stress at the base of the slope. Namely, a significant drop in the shear stress values coincides with the rise of dominant frequency from $0.8 \mathrm{~Hz}$ up to $8 \mathrm{~Hz}$ (blue box). For higher frequencies (red box), the shear stresses stabilise, and some fluctuations around specific values are observed. Generally, this variability may be related to the time sampling in the numerical model. However, the variability is relatively small and at an acceptable level from the geotechnical point of view. In all cases, it does not exceed the value of $3 \mathrm{kPa}$, which is associated with displacements of $<1 \mathrm{~mm}$. 

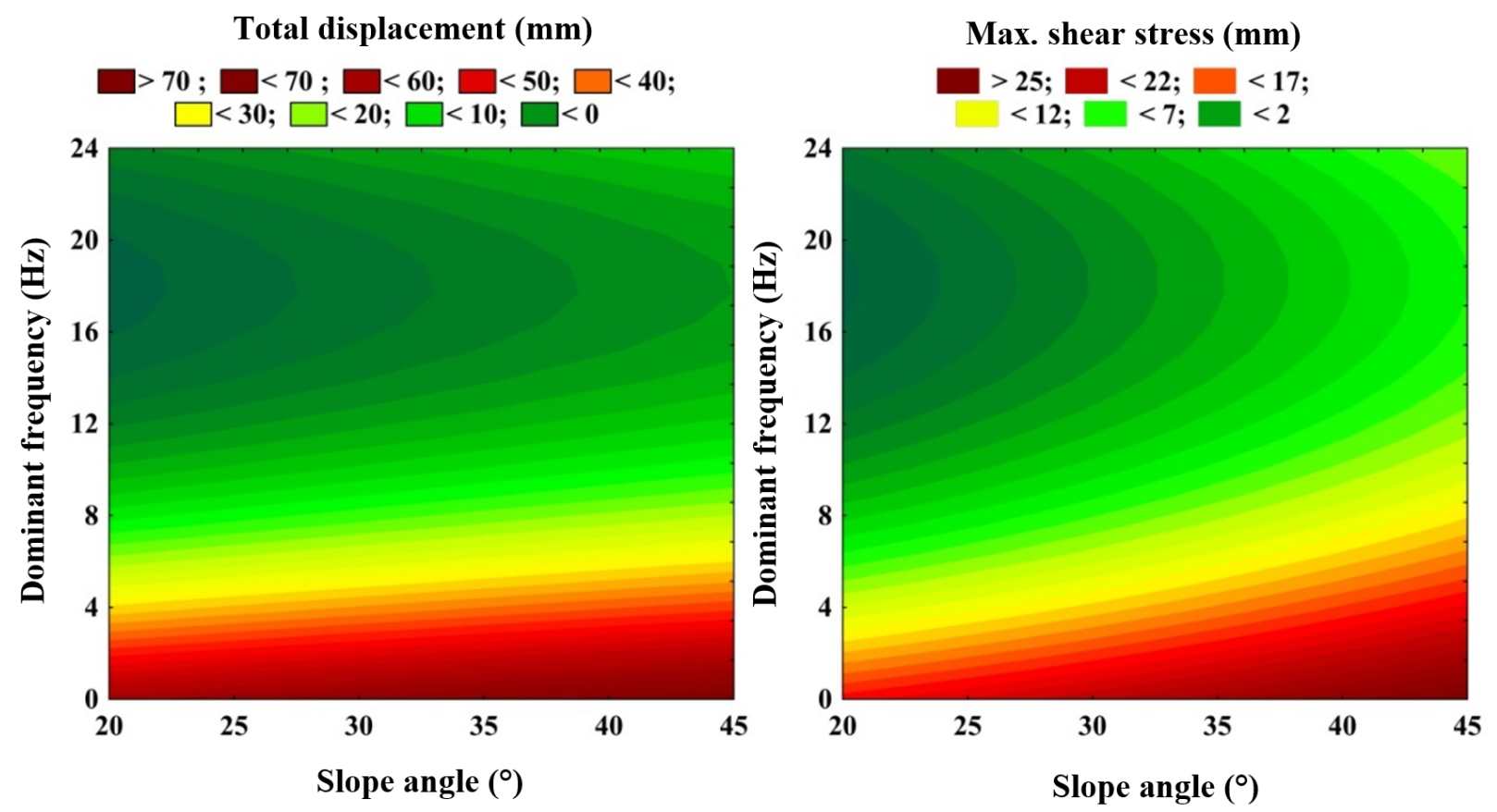

Figure 10: The RSM surface map of the relation between dominant frequency, slope angle and displacement (left) and shear stress (right) for scenarios in which the direction of seismic load is the same as the direction of slope failure.

Such small values are below the level of relevance for the stability analysis of earthen slopes subjected to dynamic load conditions.

\section{Discussion}

Results of calculations have been used to determine the importance of analysed parameters from the FEM. For this purpose, the statistical technique of experiment planning using D-optimal plans has been utilised. During analysis, three variables were considered: dominant frequency, slope angle and seismic wave propagation direction. For obtaining results, the response surface method (RSM) was incorporated. The RSM method allows examining the relationships between numerous explanatory variables and one or more response variables (Sahin et al., 2005). Results of these calculations are presented in Figures 10 and 11.

Based on the calculated RSM surface maps, it is concluded that the frequency content of seismic load has a significant impact on both displacement and shear stress at the base of the slope. In the analysed scenarios, this effect was far more significant than the influence of the slope angle. This clearly proves the legitimacy of more detailed research. We show that the frequency content of seismic waves is an essential factor that should be used to assess slope stability, due to its significant impact on stress and displacement distribution. Further detailed research on stress changes and their effect on slope stability in the conditions of additional dynamic load will enhance the reliability of the analysis.

In general, it may be assumed that the level of seismic impact and scope of harmful frequencies will be directly related to the slope geometry and its properties. Possibly, the relation between the wavelength, which is directly related to its frequency, and slope stability may be determined using FEM-based dynamic modelling. Such analyses will be a starting point for determining the risk of failure, but at the same time, may provide information on the prevention measures that need to be introduced. Moreover, additional analyses, considering the water table and the possibility of material liquefaction, need to be conducted.

The result of the analysis presented here may also be helpful during the periodical risk assessment of embankment and dam slopes located in the LGCB region in Poland. Considering only spectral characteristics (Figure 1), the biggest threat for slope stability is related to the occurrence of high-energy tremors $\left(\mathrm{E}>10^{7} \mathrm{~J}\right)$ in the distance exceeding $5 \mathrm{~km}$. In this case, most of the observed frequencies do not exceed $10 \mathrm{~Hz}$. This situation is possibly related to the selective attenuation of surface waves (Love wave and Rayleigh wave). These types of waves manifest significantly lower frequencies, and hence possibly influence the slope stability the most. 

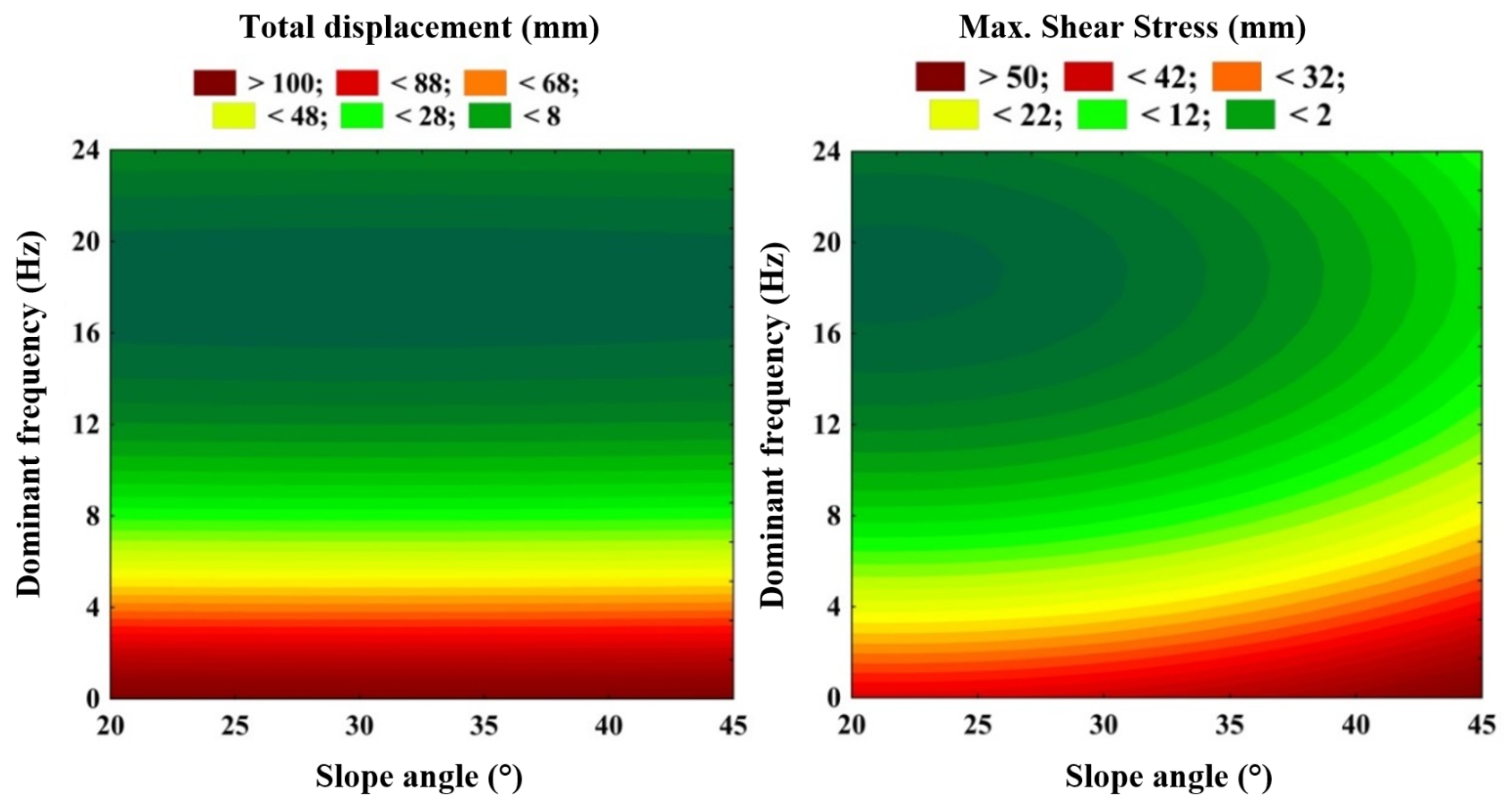

Figure 11: The RSM surface map of the relation between dominant frequency, slope angle and displacement (left) and shear stress (right) for scenarios in which the direction of seismic load is opposite to the direction of slope failure.

\section{Conclusions}

In this paper, the effect of the seismic wave's dominant frequency in FEM has been analysed in order to estimate changes of displacement and shear stresses at the bottom of the slope. In total, 180 models were calculated. Results of numerical calculations and statistical analysis have proven the importance of the dominant frequency of a seismic wave. Depending on the analysed scenario, the differences in calculated displacement for the frequency of $0.8 \mathrm{~Hz}$ may be up to 100 times higher than for $24 \mathrm{~Hz}$. In turn, when examining the shear stress, low frequencies below 1 $\mathrm{Hz}$ generate stresses that are about 16 times higher than a seismic load with a frequency of $24 \mathrm{~Hz}$. Therefore, the obtained results confirm the importance and necessity of incorporation of frequency value in slope stability analysis. Potentially, frequencies of the expected seismic events should be included in the official regulations as well.

The fact that the dominant frequency of the seismic wave has been a neglected factor in geotechnical slope stability assessment so far shows gaps in the understanding of dynamic load calculation. The work presented here will help to enhance this understanding. Improving static or pseudo-static methods with frequency-dependent methods will significantly help avoid miscalculations that lead to causalities or environmental disasters.
Further work will attempt to empirically determine if the dominant frequency is truly of such impact if its changes are not characterised by harmonic distribution. For these purposes, the measured data of high-energy tremors in the near and far wavefield will be applied.

\section{References}

[1] Adiansyah, J.S., Rosano, M., Vink, S., Keir, G., 2015. A framework for a sustainable approach to mine tailings management: disposal strategies. J. Clean. Prod. 108 , 1050-1062. https://doi.org/10.1016/j.jclepro.2015.07.139.

[2] Owen, J.R., Kemp, D., Lèbre, É., Svobodova, K., Pérez Murillo G. 2020. Catastrophic tailings dam failures and disaster risk disclosure International Journal of Disaster Risk Reduction, 42, 1-10. https://doi.org/10.1016/j.ijdrr.2019.101361.

[3] Duque, M.J.F., Zapico, I., Oyarzun, R., Lopez Garcia, J.A., Cubas, P. 2015. A descriptive and quantitative approach regarding erosion and development of landforms on abandoned mine tailings: new insights and environmental implications from SE Spain. Geomorphology. 239, 1-16 https://doi.org/10.1016/j.

[4] Schoenberg, E. 2016. Environmentally sustainable mining: the case of tailings storage facilities. Resour. Policy. 49, 119-128, https://doi.org/10.1016/j. resourpol.2016.04.009.

[5] Gobla, M. 2017. Risk analysis for evaluation of mine impounded water. Annu. Conf.Expo: Soc. Min., Metall. Explor. 1, 561-564. 
[6] International Commission On Large Dams, The World Register of Dams, https://www.icold-cigb.org/GB/world_register/ world_register_of_dams.asp (accessed 1 March 2021).

[7] Azam, S., Li, Q. 2010. Tailings dam failures: a review of the last one hundred years, Geotechnical News, 50-53, online: http:// ksmproject.com/wp-content/uploads/2017/08/Tailings-DamFailures-Last-100-years-Azam 2010.pdf

[8] Chambers, D.M. Higman B. 2011. Long-term Risk of Tailings Dam Failure. online: http://www.csp2.org/technical-reports (accessed 1 March 2021).

[9] Pytel, W. 2010. Current practice in tailings ponds risk assessment. Cuprum. 2(55), 5-41.

[10] Rico, M., Benito, G., Salgueiro, A.R., Díez-Herrero, A., Pereira H.G. 2008. Reported tailings dam failures. A review of the European incidents in the worldwide context. J. Hazard Mater. 152(2), 846-852, https://doi.org/10.1016/j. jhazmat.2007.07.050.

[11] Glotov, V.E., Chlachula, J., Glotova, L.P., Little, E. 2018. Causes and environmental impact of the gold-tailings dam failure at Karamken, the Russian Far East. Eng. Geol. 245, 236-247, https://doi.org/10.1016/j.enggeo.2018.08.012.

[12] Turi, D., Pusztai, J., Nyari, I. 2013. Causes and Circumstances of Red Mud Reservoir Dam Failure in 2010 at MAL Zrt Factory Site in Ajka, Hungary, International Conference on Case Histories. Geotechnical Engineering, Missouri University of Science and Technology 'Scholars' Mine, 2013. https://scholarsmine.mst. edu/icchge/7icchge/session03/10/.

[13] Roche, Ch. Thygesen, K. Baker, E. 2017. Mine Tailings Storage, Safety Is No Accident, United Nations Environment Programme and GRID-Arendal, Nairobi and Arendal.

[14] Vogel, A. 2013. Failures of dams - challenges to the present and the future. IABSE Workshop on Safety, Failures and Robustness of Large Structures, Inter. Assoc.Bridge Struct. Eng. 178-185.

[15] World Information Service on Energy (WISE), 2019. WISEUranium Project, Chronology of Major Tailings Dam Failures, 2019, online:https://www.wise-uranium.org/mdaf.html. (accessed 1 March 2021).

[16] Natural Resources Governance Institute (NRGI), 2017 Resource Governance Index, 2017. Available at: https:// api.resourcegovernanceindex.org/system/documents/ documents/000/000/046/original/2017. (accessed 1 March 2021).

[17] Dhungana, P., Wang, F. Relationship between seepage water volume and total suspended solids of landslide dam failure caused by seepage: an experimental investigation. Geoenviron Disasters 7, 13 (2020). https://doi.org/10.1186/s40677-0200144-6

[18] Myhre, G., Alterskjær, K., Stjern, C.W. et al. Frequency of extreme precipitation increases extensively with event rareness under global warming. Sci Rep 9, 16063 (2019). https://doi. org/10.1038/s41598-019-52277-4

[19] Fuławka, K., Stolecki, L., Jaśkiewicz-Proć, I., Pytel, W., Mertuszka, P. 2019. Time-Frequency Characteristic of Seismic Waves Observed in the Lower Silesian Copper Basin, 19th International Multidisciplinary Scientific Geoconference SGEM 2019: Conference Proceedings. Volume 19. Science and Technologies in Geology, Exploration and Mining. Issue 1.3, s. 693-700. https://doi.org/10.5593/sgem2019/1.3/S03.088

[20] Fuławka, K., Stolecki, L., Jaśkiewicz-Proć, I., Pytel, W., Mertuszka, P. 2020. The analysis of seismic load charactresitic observed in the Lower Silesian Copper Basin. SWS Journal of Earth \& Planetary Sciences, 2(2), 35-49. https://doi. org/10.35603/eps2020/issue2.03

[21] Domańska, D., Wichur, A. 2006. Method of assessment of stability of embankment and slopes on the basis of inclinometric measurements. GEOINŻYNIERIA drogi mosty tunele. 4(11), 36-40.

[22] Suddle, S., 2009. The weighted risk analysis, Safety Science. 47(5),668-679.

[23] Aven, T., 2010. On how to define, understand and describe risk, Reliability Engineering \& System Safety. 95(6), 623-631

[24] Adamo, N., Al-Ansari, N., Sissakian, V., Laue, J., Knutsson, S. 2020. Dam Safety and Earthquakes. Journal of Earth Sciences and Geotechnical Engineering. 10(6), 79-132.

[25] United State Committee on Large Dams (USCOLD), 2000. Observed Performance of Dams during Earthquakes. Volume II 5- 20 Online: http://www.ussdams.org/wp-content/ uploads/2016/05/ObservedPerformancell_V2.pdf (accessed 1 March 2021)

[26] United States Society on Dams (USSD). 2014. Observed Performance of Dams During Earthquakes Volume III. Online: https://damfailures.org/wp-content/uploads/2018/02/ EQPerfo2_v3.pdf (accessed 1 March 2021)

[27] Agurto-Detzel, H.; Bianchi, M.; Assumpção, M.; Schimmel, M.; Collaço, B.; Ciardelli, C.; Barbosa, J. R.; Calhau, J. 2016. The tailings dam failure of 5 November 2015 in SE Brazil and its preceding seismic sequence. Geophysical Research Letters, 43(10), 4929-4936. https://doi.org/10.1002/2016GL069257

[28] Castañeda, J., Bustamante, T., Perez, F., Romanel, C. 2013. A Seismic Hazard Assessment for a Tailing Dam Site in Minas Gerais - Brazil, 13th International Congress of the Brazilian Geophysical Society \& EXPOGEF, Rio de Janeiro, Brazil, 26-29 August 2013,62-67. https://doi.org/10.1190/sbgf2013-362.

[29] Adamczyk, J. 2012. Characteristics of chosen tailings 'dams' failures. Cuprum. 3(64), 65-78.

[30] Jibson, R.W. 2011. Methods for assessing the stability of slopes during earthquakes-A retrospective. Engineering Geology, 122(1-2), 43-50. https://doi.org/10.1016/j.enggeo.2010.09.017

[31] Santamarina, J.C., Torres-Cruz, L.A., Robert, C. Bachus. 2019. Why Coal Ash and Tailings Dam Disasters Occur. Science, 364 (6440), 526-28. https://doi.org/10.1126/science.aax1927.

[32] Guterch, B., 2009. Seismicity in Poland in the light of historical records, Przegląd Geologiczny, 57(6), 2009.

[33] Mirek, K., Mirek, J., 2011. Correlation between ground subsidence and induced mining seismicity, Upper Silesia Coal Basin Case, Polish Journal of Environmental Studies ; 20(4A),253-257.

[34] Adamczyk, J., Cała, M., Flisiak, J., Kolano, M., Kowalski, M. 2013. Slope stability analysis of waste dump in Sandstone Open Pit Osielec. Studia Geotechnica et Mechanica. 35(1), 3-18.

[35] IAEA Safety Standards Geotechnical Aspects of Site Evaluation and Foundations for Nuclear Power Plants for protecting people and the environment No. NS-G-3.6. 2004. online: https:// www-pub.iaea.org/MTCD/Publications/PDF/Pub1195_web.pdf (accessed 1 March 2021)

[36] Walling, M., Silva, W., Abrahamson, N., 2008. Nonlinear site amplification factors for constraining the NGA models. Earthquake spectra. 24(1), 243-255.

[37] Mining Scale of Intensity - GSI-2004/18, 2004, 
[38] BS EN 1998-1:2004+A1:2013 Eurocode 8: Design of structures for earthquake resistance. General rules, seismic actions and rules for buildings, 2004

[39] Coulomb, Ch. 1777. Magnetism memoire,

[40] Petterson, K.E. 1955. The early history of circular sliding surfaces. Geotechnique. 5, 275-296.

[41] Fellenius W., 1927. Erdstatische Berechnungenmit Reibung und Kohasion, Ernst, Berlin, 1927

[42] TERZAGHI C. 1925 - Erdbaumechanik auf Bodenphysikalischer Grundlage. Franz Deuticke, Liepzig-Vienna.

[43] Janbu, N. 1954. Application of composite slip surfaces for stabilityanalysis.InProceedings of the European Conference on Stabil-ity of Earth Slopes, Stockholm. Vol. 3. pp. 43-49.

[44] Bishop, A.W. (1955) "The Use of the Slip Circle in the Stability Analysis of Slopes”, Geotechnique, Great Britain, Vol. 5, No. 1, Mar., pp. 7-17

[45] Morgenstern, N.R., Price, V.E. 1965. The analysis of the stability of general slip surfaces. Géotechnique, 15(1): 79-93.

[46] Spencer, E. 1967. A method of analysis of the stability of embankments assuming parallel interslice forces. Géotechnique, 17(1): 11-26.

[47] Melo, C., Sharma, S. 2004 Seismic coefficients for pseudostatic slope analysis. In: 13th World conference on earthquake engineering, Vancouver, Canada

[48] Choudhury, D., Basu, S. Bray, J.D. 2007. Behaviour of Slopes under Static and Seismic Conditions by Limit Equilibrium Method. Embankments, Dams and Slopes: Lessons from the New Orleans Levee Failures and Other Current Issues. GSP 161.

[49] Hazari, S., Ghosh, S., Richi, S. 2020. A Comparative Study of Soil Slope Stability Under Seismic Loading Condition. In: Latha Gali M., Raghuveer Rao P. (eds) Geohazards. Lecture Notes in Civil Engineering, vol 86. Springer, Singapore. https://doi. org/10.1007/978-981-15-6233-4_2

[50] Liu, S.Y., Shao, L.T., Li, H.J. 2015. Slope stability analysis using the limit equilibrium method and two finite element methods, Computers and Geotechnics. 63, 291-298. https://doi. org/10.1016/j.compgeo.2014.10.008.

[51] Cheng, Y.M., Lansivaara, T., Wei, W.B., 2007. Two-dimensional slope stability analysis by limit equilibrium and strength reduction methods. Comput. Geotech. 34(3), 137-150.

[52] Griffiths, D.V. Lane, P.A. 1999. Slope stability analysis by finite elements. Géotechnique. 49(3), 387-403. https://doi. org/10.1680/geot.1999.49.3.387

[53] Zheng, H., Liu, D.F., Li, C.G. 2005. Slope stability analysis based on elasto-plastic finite element method Int J Numer Meth Eng. 64(14), 1871-1888. https://doi.org/10.1016/j. compgeo.2006.10.011

[54] Zienkiewicz, O.C., Humpheson, C., Lewis, R.W. 1975. Associated and nonassociated. Visco-plasticity and plasticity in soil mechanics. Geotechnique 25(4), 671-689.

[55] Duncan, J.M. 1996. State of the art: limit equilibrium and finiteelement analysis of slopes. J. Geotech. Eng. 122(7), 577-596.

[56] Shangyi, Z., Yingren, Z., Weidong, D. 2003. Stability analysis on jointed rock slope by strength reduction FEM. Chin. J. Rock Mech. Eng. 2(020)

[57] Yingren, Z., Shangyi, Z.2004. Application of strength reduction FEM in soil and rock slopes. Chin. J. Rock Mech. Eng. 23(19), 3381-3388.

[58] Hammah, R.E., Yacoub, T.E., Corkum, B., Wibowo, F., Curran, J.H. 2007. Analysis of blocky rock slopes with finite element shear strength reduction analysis. In: Proceedings of the 1st Canada-U.S. Rock Mechanics Symposium, Vancouver, Canada,329-334.

[59] Chiwaye, H. 2010. A Comparison of the Limit Equilibrium and Numerical Modelling Approaches to Risk Analysis for Open-Pit Mine Slopes. Journal- South African Institute of Mining and Metallurgy.110(10), 571-580

[60] Kucewicz, M., Baranowski, P., Małachowski, J. 2021. Dolomite fracture modeling using the Johnson-Holmquist concrete material model: Parameter determination and validation, Journal of Rock Mechanics and Geotechnical Engineering, 13(2), 335-350, https://doi.org/10.1016/j.jrmge.2020.09.007.

[61] Baranowski, P., Mazurkiewicz, Ł., Małachowski, J., Pytlik, M. 2020. Experimental testing and numerical simulations of blastinduced fracture of dolomite rock. Meccanica. 55, 2337-2352 (2020). https://doi.org/10.1007/s11012-020-01223-0

[62] Pytel, W., Fuławka, K., Mertuszka, P., Szumny, M., Koziarz, E. 2019. Amplitude and Frequency Characteristics of Rotational Ground Motions Generated by Paraseismic Events, 19th International Multidisciplinary Scientific Geoconference SGEM 2019 : Conference Proceedings. Volume 19. Science and Technologies in Geology, Exploration and Mining, Issue 1.3, s. 31-38. https://doi.org/10.5593/sgem2019/1.3/S03.004

[63] Zhao, J. 2000. Applicability of Mohr-Coulomb and HoekBrown strength criteria to the dynamic strength of brittle rock. International Journal of Rock Mechanics and Mining Sciences. 37(7), 1115-1121

[64] Owen, D.R.J., Hinton, E. 1980. Finite Elements in PlasticityTheory and Practice Pineridge Press, Swansea.

[65] Pietruszczak, S. 2010. Fundamentals of Plasticity in Geomechanics. CRC Press.

[66] Labuz, J. F., Zang, A. 2012. Mohr-Coulomb failure criterion. The ISRM Suggested Methods for Rock Characterization, Testing and Monitoring. 2007-2014, 227-231.

[67] RocScience, 2021, Dynamic Theory Manual, available online: https://www.rocscience.com/help/rs2/theory/dynamic_ theory_manual.htm

[68] Kuhlemeyer, R.L., Lysmer, J. 1973. Finite Element Method Accuracy for Wave Propagation Problems, Journal of the Soil Mechanics and Foundations Division. 99(5), 421-427.

[69] Sahin Y, Riza Motorcu A. Surface Roughness Model for Machining Mild Steel with Coated Carbide Tool. Materials \& Design, 2005, 26, 321-326. https://doi.org/10.1016/j. matdes.2004.06.015. 